\title{
Energy demand analysis according to window size and performance for Korean multi-family buildings
}

\author{
Jung-Ho Huh and Sun-Hye Mun \\ Department of Architectural Engineering, University of Seoul, Seoul, Korea
}

http://dx.doi.org/10.5659/AIKAR.2013.15.4.201

\begin{abstract}
Special attention is required for the design of windows due to their high thermal vulnerability. This paper examines the problems that might arise in the application of the $\mathrm{u}$-value, by reflecting the changes in the $\mathrm{u}$-value of the window, depending on the window-to-wall ratio obtained in an energy demand analysis. Research indicates that the $\mathrm{u}$-value of a window increases with an increase in the difference between the $\mathrm{u}$-values of the frames and the glass. Relative to the changes in the $\mathrm{u}$-value of the windows, the energy demand varied from $1.3 \%$ to $9.3 \%$. Windows with a g-value of 0.3 or 0.5 displayed a higher energy demand than windows with a g-value of 0.7 . Therefore, when the difference between the performance of the glass and the frame is significant, especially when the g-value is small, a modified heat transmission coefficient should be applied to the window size during the evaluation of the building energy demand.
\end{abstract}

Keywords: g-value; Heating and Cooling Energy Demand; WWR (Window-to-Wall-Ratio)

\section{INTRODUCTION}

There has been no doubt that window is thermally the most vulnerable part among the building envelopes. Design standard varies for each component of building structures. Although window wall design has several standards, a single value is simply set as a design standard of window.

A window is composed of glass, a frame, and a spacer. Because there is a thermal difference among the elements of a window, a change in size causes performance variation. However, the performance evaluation of windows is conducted only on a finished product with a specific size. Even if the thermal performance of frame is low, entire window can meet the standard as long as the glass shows high performance.

Because the certification of window performance is based on a fixed size, a uniform window performance criterion applies to the energy analysis of a building. Therefore, variance of performance is not considered even if the window size changes.

The purpose of this study is to analyze the building energy impact of subdividing window performance criteria. For this purpose, window performance was subdivided into different parts, and the

Corresponding Author : Sun-Hye Mun

Department of Architectural Engineering, University of Seoul,

Seoul, Korea

Tel : +82-2-6490-5561 e-mail : sunhye.mun@uos.ac.kr

This is an Open Access article distributed under the terms of the Creative Commons Attribution Non-Commercial License (http://creativecommons. org/licenses/by-nc/3.0/) which permits unrestricted non-commercial use, distribution, and reproduction in any medium, provided the original work is properly cited. performance that was calculated depending on the window size was put into a simulation in order to analyze the cooling and heating energy demands.

\section{OBJECT DESCRIPTION}

(1) Visual Access and Exposure Model

To date, double-glazed double sliding windows have been mainly used in Korean residential buildings. This is mainly due to cultural reasons. Most people prefer large windows that can be opened, although the air tightness of sliding windows is very weak. However, with the increasing importance of saving energy, the application of a system window such as T/T (Tilt and Turn) has been recommended as an alternative to a sliding window.

Two types of windows were selected based on the current Korean window market (see Figure 1). The first, a double-glazed double window, was the window type most frequently used in Korean residential buildings from 2001 to 2009. The heat transmission coefficient (u-value) of this window improved from 3.4 to $2.1 \mathrm{~W} /$ $\mathrm{m} 2 \mathrm{~K}$ in compliance with Korean energy-saving design criteria. A comparison of the performance before and after the improvement shows that the frame material was the same aluminium frame but the performance was improved by applying low-e coating to the third plane glass, although the previous glass was $6 \mathrm{~mm}$ Clear +12 $\mathrm{mm}$ Air $+6 \mathrm{~mm}$ Clear. In other words, the performance improvement was concentrated in the glass rather than the frame, so there was a significant difference between the performance of the glass and the frame. The second window type is the tripleglazed system window. This type of window is not often used in Korean residential buildings due to its high cost. However, it was selected for analysis because it was determined that there was a high possibility of future applications and a strong likelihood that the 
insulation standard could be strengthened. The frame material of the system window is PVC (Poly Vinyl Chloride).

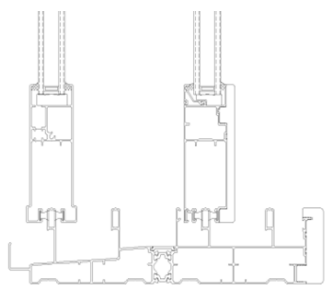

(a)

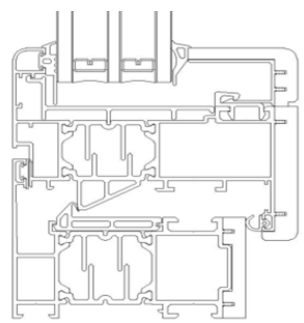

(b)
Figure 1. Window cross-sections. (a) Double-glazed double window, (b) Triple-glazed system window

(2) Building

In residential buildings, energy loss and gain rate depend on household location. This is because heat loss increases as the area of the exterior wall facing the open air increases. For this study, we selected the middle floor as a target in order to exclude the energy difference generated by household location.

The target building was a 15-floor apartment building facing due south. There were two apartments per floor around an elevator, and the ratio of the area for exclusive use space for each household was $84 \mathrm{~m}^{2}$, which is the most common household area in Korea. After the removal of balconies became legal in December of 2005, the number of households expanding balconies increased rapidly. To reflect this popular trend, the analysis was performed by selecting the household whose heating area was $100.13 \mathrm{~m}^{2}$ after balcony removal. Floor height was $2.8 \mathrm{~m}$ and ceiling height was $2.38 \mathrm{~m}$. Based on the research results of Korean residential buildings, the size of the target building could be considered a proper representation of Korean residential buildings in general .

Figure 2 shows the floor plan and isometric of target household. Each household consists of three bedrooms, a living room, a kitchen, and two bathrooms. The analysis was conducted everywhere except non-conditioned areas such as the balcony, the bathroom, the shelter space, the elevator shaft, and the staircase.

In Korea, the Energy Saving Design Criteria has been strengthened since 2009, and the insulation performance of exterior walls and windows was enhanced by $24 \%$ and $45 \%$, respectively, compared to that of 2008, and it is expected to be strengthened even more in the future (MOLIM 1992-2012). The exterior wall performance of the target building was based on the design standard of 2009, and the roof and floor were set to adiabatic for excluding the influence of the household location.

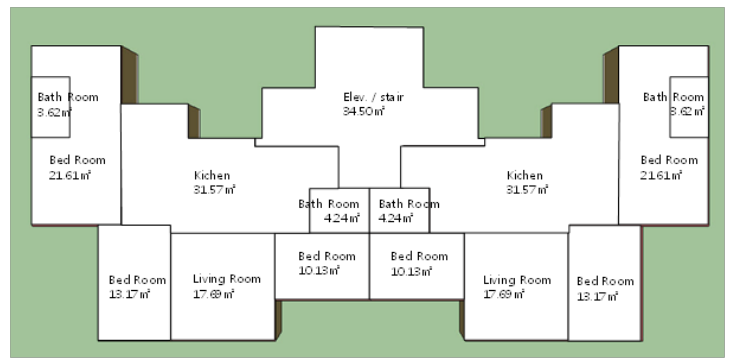

(a)

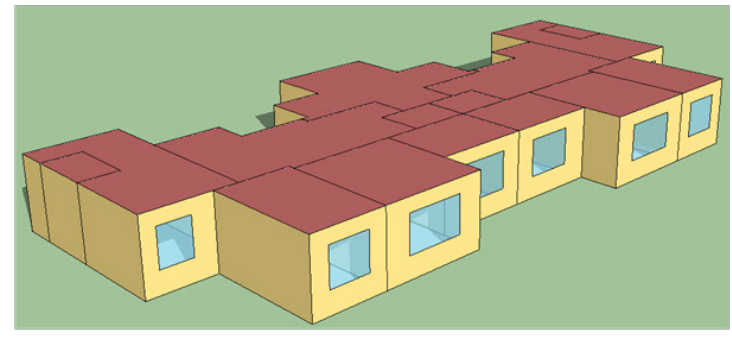

(b)

Figure 2. (a) Floor plan and (b) Isometric

\section{SIMULATION}

(1) Window system performance analysis

The thermal performance of a window can be evaluated subdividing into the $\mathrm{u}$-value of the glass and frame, and linear thermal transmittance in the spacer. The values of frame and window thermal transmittance have been adopted according to EN ISO 10077-2 Annex C. The u-value of the frame was evaluated using THERM. Firstly frame Modeling was performed with an insulation panel $(\lambda=0.035 \mathrm{~W} / \mathrm{m} \cdot \mathrm{K})$ instead of the glass to the frame section to find out $\mathrm{u}$-value of the frame. After calculating the two-dimensional thermal coupling coefficient $\mathrm{L}^{2 \mathrm{D}}$, the $\mathrm{u}$-value of the frame was calculated by applying its result to Equation (1) proposed in ISO 10077-2 Annex C,

$$
U_{f}=\left(L^{2 D}-U_{p} b_{p}\right) / b_{f}
$$

where $U_{p}$ is the thermal transmittance of the panel, $b_{p}$ and $b_{f}$ are visible width of the panel and projected with of the frame section, respectively.

For the evaluation of the window's u-value, the WINDOW program was used. After the individual performances of the frame and the glass were determined, the window system was evaluated. The window, including the glass part, was modeled in THERM and the $\mathrm{L}^{2 \mathrm{D}}$ was calculated at that time. Linear thermal transmittance $(\Psi \mathrm{g})$ of the glazing system generated in the spacer part was calculated by inputting the result to Equation (2). For a double-glazed double window, it was calculated by applying Equation (3) proposed in ISO 10077-1,

$$
\begin{gathered}
\psi_{g}=L^{2 D}-U_{f} b_{f}-U_{g} b_{g} \\
U_{w}=1 /\left(1 / U_{w 1}-R_{s i}+R_{s}-R_{s e}+1 / U_{w 2}\right)
\end{gathered}
$$

where $U_{f}$ is the thermal transmittance of the frame from Equation(1). $\mathrm{U}_{\mathrm{g}}$ is the thermal transmittance of the glazing from WINDOW program and $b_{g}$ is visible width of the glazing. $\mathrm{R}_{\mathrm{si}}$ and $\mathrm{R}_{\mathrm{se}}$ are the internal and external surface resistances of windows, respectively. $R_{s}$ is thermal resistance of the space between the glazing in the two windows. $\mathrm{U}_{\mathrm{w} 1}$ and $\mathrm{U}_{\mathrm{w} 2}$ are the thermal transmittance of the external and internal window, respectively. 
(2) Building energy analysis

For building energy analysis, EnergyPlus7.0 was used. Weather data are one of the most important input values to analyze building energy. In this study, IWEC(International Weather for Energy Calculation) weather data of Seoul area was used (Lee et al. 2010; ISO 15927-4 2005). The weather conditions in the Seoul area belong to level $4 \mathrm{~A}$ in climate classification based on the ASHRAE Standard (ASHRAE 2004). Figure 3 shows the outdoor air temperature and horizontal solar radiation of IWEC weather data of Seoul. Outdoor air temperature is the average value for month, and horizontal solar radiation is the cumulative value for month.

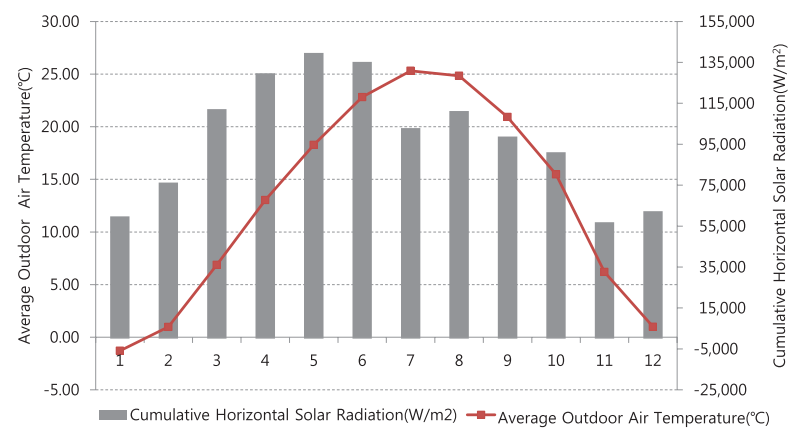

Figure 3. Weather data of Seoul

Table 1 shows the input data for calculating the energy consumption of the target household (Ihm et al. 2012). It was assumed that there are no occupants in the house from 9-12 am, and $1-6 \mathrm{pm}$, and the air is conditioned at all other hours.

Table 1. Characteristics of a housing unit in South Korea

\begin{tabular}{|c|c|c|}
\hline \multicolumn{2}{|c|}{ Parameter } & Value \\
\hline \multicolumn{2}{|c|}{ Floor area } & $100.13 \mathrm{~m}^{2}$ \\
\hline \multicolumn{2}{|c|}{ Infiltration } & $0.5 \mathrm{ACH}$ \\
\hline \multicolumn{2}{|c|}{ Thermostat settings } & $\begin{array}{l}\text { Heating (Nov.-Mar.): } 20^{\circ} \mathrm{C} \text {, } \\
\text { Cooling (July-Sep.): } 26^{\circ} \mathrm{C}\end{array}$ \\
\hline \multirow{2}{*}{ Internal gains } & lights & $13 \mathrm{~W} / \mathrm{m}^{2}$ \\
\hline & equipment & $5 \mathrm{~W} / \mathrm{m}^{2}$ \\
\hline
\end{tabular}

\section{RESULTS AND DISCUSSION}

(1) Window performance

Table 2 shows the results of WINDOW and THERM in calculating the insulation performance of each glass, frame, and the overall $\mathrm{u}$-value of a window was derived from the case in which the size of the window is $2 \mathrm{~m} \times 2 \mathrm{~m}$, which is the certified sample size of Korean windows.

The performance analysis result of each component revealed that frame mainly causes the performance differences between double-glazed double windows and triple-glazed windows. The window (A) system shows that there is a significant gap between the performance of the frame and the glass. However, the window (B) system shows a similar performance for both the frame and the glass.
Table 2. Window's u-value

\begin{tabular}{|c|c|c|c|c|c|}
\hline \multirow{2}{*}{\multicolumn{3}{|c|}{ Segment }} & \multicolumn{2}{|c|}{ (A) Double-glazed double } & \multirow{3}{*}{$\begin{array}{c}\begin{array}{c}\text { (B) Triple- } \\
\text { glazed }\end{array} \\
1.269\end{array}$} \\
\hline & & & $\mathrm{U}_{\mathrm{w} 1}$ & $\mathrm{U}_{\mathrm{w} 2}$ & \\
\hline \multirow{2}{*}{ Frame } & $\mathrm{U}_{\mathrm{f}}$ & $\mathrm{W} / \mathrm{m}^{2} \cdot \mathrm{K}$ & 11.570 & 12.730 & \\
\hline & $A_{f}$ & $\mathrm{~m}^{2}$ & 0.496 & 0.945 & 0.496 \\
\hline \multirow{2}{*}{$\begin{array}{c}\text { Linear } \\
\text { thermal } \\
\text { transmittance }\end{array}$} & $\psi_{\mathrm{g}}$ & $\mathrm{W} / \mathrm{m} \cdot \mathrm{K}$ & 0.040 & 0.000 & 0.050 \\
\hline & $1_{g}$ & $\mathrm{~m}$ & 3.488 & 3.496 & 3.488 \\
\hline \multirow{2}{*}{ Glasses } & $\mathrm{U}_{\mathrm{g}}$ & $\mathrm{W} / \mathrm{m}^{2} \cdot \mathrm{K}$ & \multicolumn{2}{|c|}{2.145} & 1.023 \\
\hline & $\mathrm{A}_{\mathrm{g}}$ & $\mathrm{m}^{2}$ & \multicolumn{2}{|c|}{3.504} & 3.504 \\
\hline $\begin{array}{c}\text { Single } \\
\text { window }\end{array}$ & $\mathrm{U}$ & $\mathrm{W} / \mathrm{m}^{2} \cdot \mathrm{K}$ & 3.348 & 4.645 & \multirow{2}{*}{1.090} \\
\hline Total window & $\mathrm{U}$ & $\mathrm{W} / \mathrm{m}^{2} \cdot \mathrm{K}$ & \multicolumn{2}{|c|}{1.900} & \\
\hline
\end{tabular}

Changes in u-value due to changes in the size of the window can be obtained by applying previously calculated values to the following equation(ISO 10077-1),

$$
U_{w}=\frac{\sum U_{g} A_{g}+\sum U_{f} A_{f}+\sum l_{g} \psi_{g}}{\sum A_{g}+\sum A_{f}}
$$

where $A_{g}$ and $A_{f}$ are the area of glazing and frame. $l_{g}$ is the glazing perimeter, and $\Psi_{\mathrm{g}}$ is the linear thermal transmittance due to the combined thermal effects of glazing, spacer and frame. When considering the performance change of a window that is due to an increase in its size, one should keep in mind that the u-value relatively decreases because of the increase in the portion of the glass. Therefore, when the performance difference between the glass and the frame is significant, the change in the u-value depending on the increase in area is also significant. When the performance of window(A) was compared to the performance of a $2 \mathrm{~m} \times 2 \mathrm{~m}$ window that has been certified, it was shown that the performance difference was about $\pm 1.0 \mathrm{~W} / \mathrm{m}^{2} \cdot \mathrm{K}$. However, window $(\mathrm{B})$, which has a similar performance of the glass and the frame, is not affected by window size.

The g-value of windows is also one of the factors affecting the energy consumption of a building. Like the u-value, if the total area of the window increases, the overall g-value changes by as much as the size of the window occupied by the frame in the g-value of the glass. This study proceeded with research into the assumption that the g-value of glass is that of the window. When establishing the scope of the g-value, the study researched the u-value and the g-value of Korean glass makers and selected the case in which the g-value is $0.3,0.5$, and 0.7 .

The sizes of the windows used to obtain the changes in the u-value are shown in Table 3. The height of the southern window was fixed and its width was changed by $0.6 \mathrm{~m}$ increments. As a result, six cases were analyzed, and the $\mathrm{u}$-value of individual windows at this time were calculated and applied, as shown in Table 4. 
Table 3. Change of the southern size of the window

\begin{tabular}{|c|c|c|c|c|c|c|}
\hline Segment & case 1 & case 2 & case3 & case 4 & case 5 & case6 \\
\hline $\begin{array}{l}\text { Configuration } \\
\text { of the size } \\
\text { of the window }\end{array}$ & (1) $\times 8 \mathrm{ea}$ & (2) $\times 8 \mathrm{ea}$ & (3) $\times 8 \mathrm{ea}$ & $\begin{array}{l}\text { (3) } \times 2 \mathrm{ea} \\
\text { (4) } \times 6 \mathrm{ea}\end{array}$ & $\begin{array}{l}\text { (3) } \times 2 \mathrm{ea} \\
\text { (4) } \times 2 \mathrm{ea} \\
(5) \times 4 \mathrm{ea}\end{array}$ & $\begin{array}{l}\text { (3) } \times 2 \mathrm{ea} \\
\text { (4) } \times 2 \mathrm{ea} \\
\text { (5) } \times 2 \mathrm{ea} \\
\text { (6) } \times 2 \mathrm{ea}\end{array}$ \\
\hline $\begin{array}{c}\text { size of the } \\
\text { window }\left(\mathrm{m}^{2}\right)\end{array}$ & 10.56 & 21.12 & 31.68 & 39.60 & 44.88 & 47.52 \\
\hline WWR(\%) & 14.10 & 28.21 & 42.31 & 52.88 & 59.94 & 63.46 \\
\hline
\end{tabular}

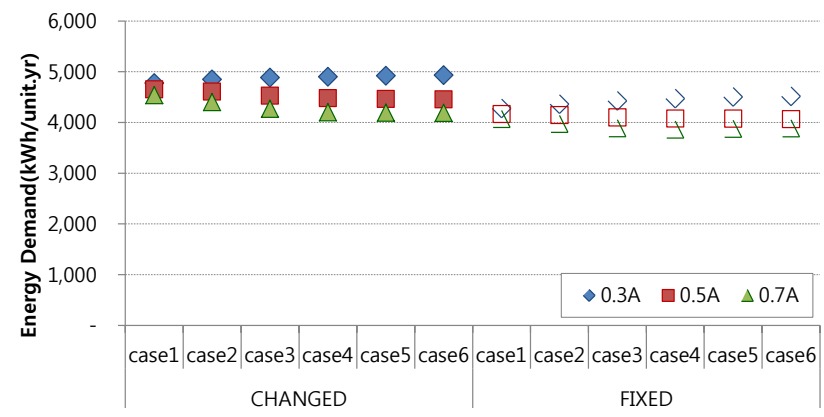

(A) Window (A)
Table 4. Change of the $\mathrm{u}$-value based on the size of the window

\begin{tabular}{|c|c|c|c|}
\hline & & \multicolumn{2}{|c|}{ u-value $\left(\mathrm{W} / \mathrm{m}^{2} \cdot \mathrm{K}\right)$} \\
\hline & & window(A) & window(B) \\
\hline certified size & $4 \mathrm{~m}^{2}$ & 1.90 & 1.09 \\
\hline \multirow{6}{*}{ south } & (1) $1.32 \mathrm{~m}^{2}$ & 3.77 & 1.37 \\
\hline & (2) $2.64 \mathrm{~m}^{2}$ & 2.76 & 1.24 \\
\hline & (3) $3.96 \mathrm{~m}^{2}$ & 2.42 & 1.20 \\
\hline & (4) $5.28 \mathrm{~m}^{2}$ & 2.24 & 1.18 \\
\hline & (5) $6.60 \mathrm{~m}^{2}$ & 2.14 & 1.17 \\
\hline & (6) $7.92 \mathrm{~m}^{2}$ & 2.07 & 1.16 \\
\hline \multirow{2}{*}{ north } & $1.75 \mathrm{~m}^{2}$ & 3.02 & 1.31 \\
\hline & $2.7 \mathrm{~m}^{2}$ & 4.00 & 1.30 \\
\hline
\end{tabular}

Figure 3. Total energy demand

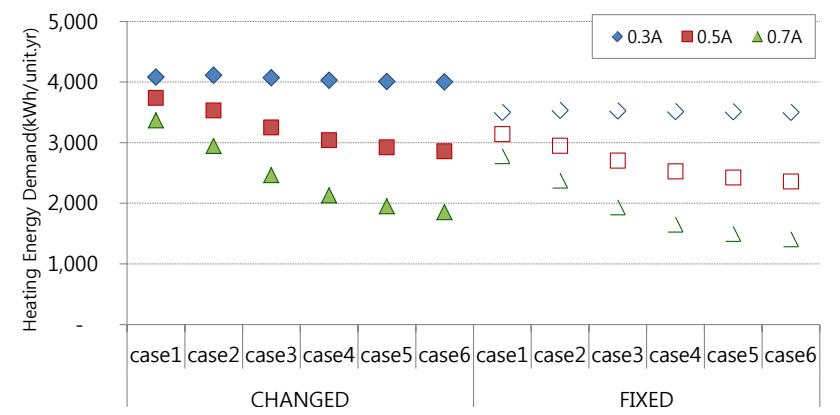

(A) Window (A)

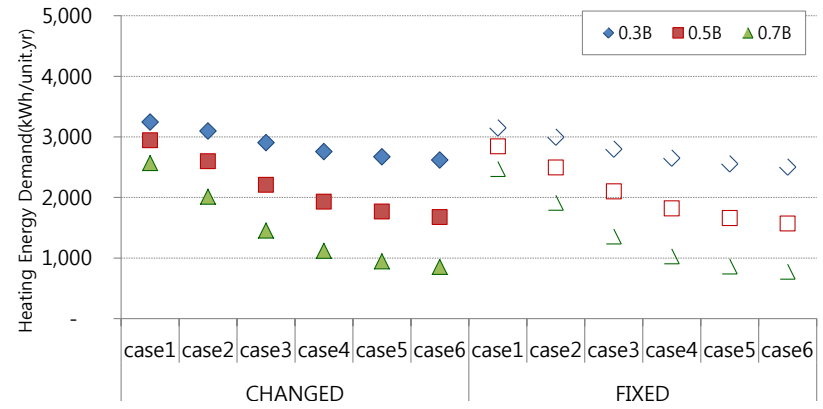

(B) Window (B)

Figure 4. Heating energy demand

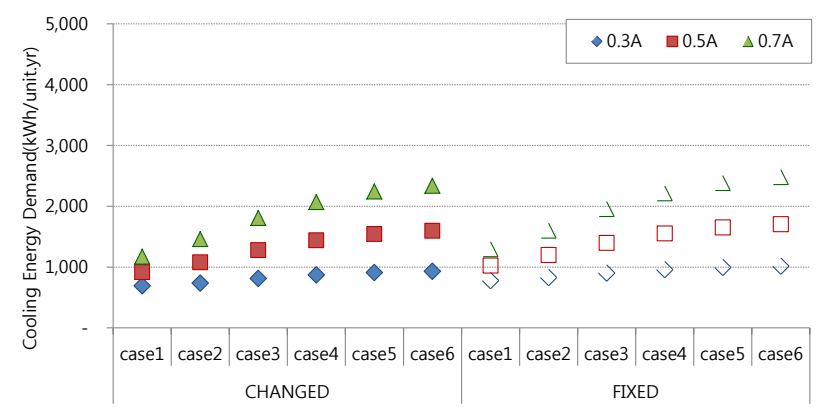

(A) Window (A)

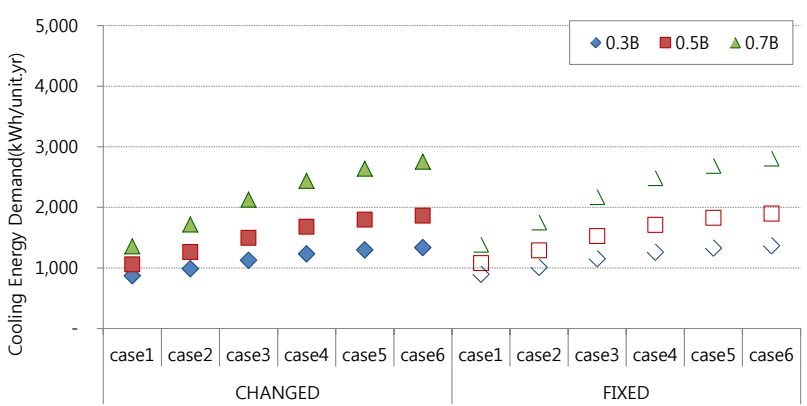

(B) Window (B)

Figure 5. Cooling energy demand 
(2) Building Energy

When analyzing the energy demand of the target household, the heat transmission coefficient of the windows varied depending on whether the window performance was subdivided. The calculation results of cooling and heating energy demands on each window size and the g-value are as follows.

As the size of the window increases, the rate of heating demand decreases in the entire demand, and as the g-value increases, the same tendency is shown. The decrease of heating demand rate depending on the increase in the size of the window was significant when the g-value increased. Due to superior insulation performance, window (B) outperformed window (A) demanding $10 \%$ less heating energy.

If heating and cooling were separately considered, heating was disadvantageous when performance was fixed, meanwhile, cooling was advantageous. It was determined that both heating and cooling showed a larger energy increase depending on the change of g-value than an energy consumption increase depending on the increase in the size of the window.

In addition, the cooling and heating energy demand was much higher when the change of heat transmission coefficient depending on the size of the window was reflected. This is because, as shown in Table 4, its heat transmission coefficient is higher than that of the certified size. Table 5 shows the differences in energy demand. The case of window (A) shows a larger difference than that of window (B). This means that the gap increases when the performance difference between the glass and the frame is high and the g-value is high.

When window performance is low and the performance difference between the glass and the frame is high, as shown for window (A), the variance of the heat transmission coefficient is wide because the change in the size of the glass is large. In spite of this, if the performance of a certified window is reflected in the building energy analysis, the energy analysis result may differ by $1.3 \% \sim 9.3 \%$. In other words, when interpreting structural energy, the above gap can be reduced only by substituting the heat transmission coefficient appropriate to the size of the window.

\section{CONCLUSION}

This study compared two cases, where the heat transmission coefficient is applied uniformly, and where the coefficients change according to the size of the window. For the comparison, the performance of each component of the window was segmented, using the WINDOW and the THERM programs. Next, the changes in the performance of the window system when the size of the window changes, were reviewed, and the gap obtained by applying the result to an analysis of cooling and heating energy was investigated. The main results obtained from the study are as follows.

(1) If the performance of individual window components differs greatly, the insulation performance relative to changes in the window size also differs greatly. In the subject window (A), a difference of up to $\pm 1.0 \mathrm{~W} / \mathrm{m}^{2} \cdot \mathrm{K}$ was observed.

(2) In windows where the performance of individual components does not differ greatly, such as passive windows $\left(U_{w}=0.8 \mathrm{~W} / \mathrm{m}^{2} \cdot \mathrm{K}\right)$, the segmentation of components hardly influences the changes in insulation performance.
(3) When the performances of the individual window components were significantly different and the g-value was high, there was an increased effect on the building energy, due to the changes in the window performance relative to the changes in the size of the window. It was determined that the gap, depending on whether it was reflected, varied from a minimum of $1.3 \%$ to a maximum of $9.3 \%$.

(4) Therefore, it is necessary to determine whether the performances of the components change relative to changes in the size of the window. This should be used to perform accurate simulations of the building energy.

Lastly, it is expected that a more accurate analysis of the effect of changes in the g-value relative to changes in the size of the window on the building energy will become available, if the standardization study of the method to evaluate the g-value of each window component, which has been performing by various countries, is completed. In addition, as the subject window was analyzed as a single case, such changes in heat transmission may differ according to the performance of the glass or the frame.

\section{REFERENCES}

ANSI/ASHRAE/IESNA Standards 90.1- 2004. (2004) "Energy Standard for Buildings Low-Rise Residential Buildings." American Society of Heating, Refrigerating, and AirConditioning Engineers, Inc. Atlanta.

Cappelletti, F., et al. (2011) "Analysis of the influence of installation thermal bridges on windows performance: The case of clay block walls." Energy and Buildings, 43(6), 1435-1442.

EN ISO 10077-1. (2006) "Thermal performance of windows, doors and shutters - Calculation of thermal transmittance-Part1: General."

EN ISO 10077-2. (2003) "Thermal performance of windows, doors and shutters - Calculation of thermal transmittance - Part 2: Numerical method for frames."

EN ISO 15927-4 (2005) "Hygrothermal performance of buildingscalculation and presentation of climatic data-Part4: Data for assessing the annual energy for heating and cooling."

EPBD. (2010) "Directive 2010/31/EU of the European parliament and of the council of 19 may 2010 on the energy performance of buildings." Official Journal of the European Union.

Gasparella, A., et al. (2011) "Analysis and modelling of window and glazing systems energy performance for a well insulated residential building." Energy and Buildings, 43(4), 1030-1037.

Ghisi, E., and John A. Tinker. (2005) "An ideal window area concept for energy efficient integration of daylight and artificial light in buildings." Building and Environment, 40(1), 51-61.

Ihm, P., et al. (2012) "Impact of window selection on the energy performance of residential buildings in South Korea." Energy Policy, 44, 1-9.

Jaber, S. and Ajib S. (2011) "Thermal and economic windows design for different climate zones." Energy and Buildings, 43(11), 32083215.

Lee, et al. (2010) "Generation of typical weather data using the ISO Test Reference Year (TRY) method for major cities of South Korea." Building and Environment, 45, 956-963. 
MOLIT(Ministry of Land, Infrastructure and Transport) (2012) [online]. Available from: www.molit.go.kr.

Nielsen, T., Duer, K., and Svendsen, S. (2001) "Energy performance of glazings and windows." Solar Energy, 69(6), 137-143.

Su, X. and Xu, Z. (2010) "Environmental performance optimization of window-wall ratio for different window type in hot summer and cold winter zone in China based on life cycle assessment." Energy and Buildings, 42(2), 198-202.

Tsikaloudaki, K., et al. (2012) "Assessing cooling energy performance of windows for office buildings in the mediterranean zone." Energy and Buildings, 49, 192-199.

Urbikain, M. and Sala, J. (2009) "Analysis of different models to estimate energy savings related to windows in residential buildings." Energy and Buildings, 41(6), 687-695.

(Received August 30, 2013/Accepted December 5, 2013) 